\title{
Research
}

Katherine Maskell, Paula McDonald and Priyamvada Paudyal

\section{Effectiveness of health education materials in general practice waiting rooms:}

a cross-sectional study

\begin{abstract}
Background

Health education materials (HEMs) are widely used in general practice. However, there is little information on the variety of HEMs currently available to patients in the UK, or their preferences for accessing educationa materials.
\end{abstract}

\section{Aim}

To assess patients' perceptions of HEMs, and the variety and accessibility of these materials.

\section{Design and setting}

Cross-sectional study conducted in general practices in Brighton and Hove.

\section{Method}

An anonymous questionnaire was distributed to patients in the waiting room (WR). Additionally, an audit was conducted to measure the variety of the HEMs. Results were analysed using binary multiple logistic regression.

\section{Results}

In all, 556 participants (response rate 83.1\%) from 19 practices took part. The mean age of participants was 49.3 years $(S D \pm 18.9$ ) and $63 \%$ were female. Perceived usefulness of HEMs was associated with reading in the WR using written HEMs, and not having a university degree; noticeability was associated with reading in the WR, and being female; attractiveness was associated with not having a university degree and shorter waiting time. On average, WRs contained 72 posters covering 23 topics, and 53 leaflets covering 24 topics, with many outdated and poorly presented materials of limited accessibility.

\section{Conclusion}

This study found substantial variation in the amount, topicality, and quality of material available in WRs. As most patients notice HEMs and find them useful, available technology could be better utilised to widen access to HEMs. The introduction of wireless free internet (Wi-Fi) to waiting rooms should provide an opportunity to update this area.

\section{Keywords}

general practice; health education; patient education; patient information; waiting room.

\section{INTRODUCTION}

Health education materials (HEMs) in the waiting room (WR) have been associated with increased knowledge and satisfaction, and decreased anxiety among patients, 1,2 and may help to support informed decision making and patients' involvement in their care. . $^{-5}$

Health information needs to be evidence based, acceptable, useful, comprehensible, and relevant. ${ }^{6}$ The subject of HEMs has been heavily researched, but much of the evidence available in general practice is more than two decades old, ${ }^{7-10}$ or focuses on individual interventions. ${ }^{11-15}$ Little information is available on the variety of HEMs currently offered to general practice patients in the UK, or patient preferences for accessing educational materials.

\section{METHOD}

\section{Study design}

This study used a cross-sectional methodology to assess patients' opinions regarding the usefulness, noticeability, and attractiveness of HEMs in general practice WRs. The study also examined the variety and accessibility of these materials.

\section{Study setting}

The study was conducted in the WRs of general practices in Brighton and Hove. All general practices in Brighton and Hove were approached by email and telephone between February and May 2017. Between March and May 2017, one to three visits

K Maskell, MSc, medical student; P Paudyal MSc, MPH, PhD, lecturer, Department of Primary Care and Public Health and Department of Medical Education, Brighton and Sussex Medical School, University of Sussex, Brighton P McDonald, MSc, MRCGP, MFPHM, GP, Seven Dials Medical Centre, and Brighton and Sussex Medical School, University of Sussex, Brighton. Address for correspondence

Priyamvada Paudyal, Room 322, Mayfield House, were made to each practice to distribute the questionnaire and collect data. Practices were visited on different days of the week, in both morning and afternoon sessions

\section{Participants}

Patients were included if they were $>18$ years, had visited the practice location in the last 6 months, and were able to complete the questionnaire independently and in English.

\section{Data sources}

The questionnaire. The questionnaire was based on previous literature, ,9,10,16 and covered information in relation to age, sex, ethnic background, sexual orientation, smoking status, highest level of education, disability, English as a first language, number of general practice visits in the last 6 months, waiting time, use of healthrelated information, and activities in the WR (further information is available from the authors on request). The questionnaire was piloted in five individuals who had visited their doctor in the previous 2 weeks. Patients who had been in the waiting room for at least 5 minutes were approached, and, once eligibility had been confirmed, were asked to complete the questionnaire before they left the practice. Participant consent was implied by return of the questionnaire. The questionnaire took $<10$ minutes to complete.

The audit tool. Data were also collected on

Brighton and Sussex Medical School, Brighton, East Sussex BN1 9PH, UK

Email: p.paudyalabsms.ac.uk

Submitted: 4 March 2018; Editor's response: 23 April 2018; final acceptance: 29 May 2018 (c)British Journal of General Practice This is the full-length article (published online 23 Oct 2018) of an abridged version published in print. Cite this version as: $\mathbf{B r} \mathbf{J}$ Gen Pract 2018; DOI: https://doi.org/10.3399/bjgp18X699773 


\section{How this fits in}

Although existing research on the variety of health education materials (HEMs) currently available to general practice patients in the UK is limited, this study found substantial variation in the amount, topicality, and quality of HEMs, with many outdated and poorly presented materials. Patients notice HEMs and find them useful, but investment and leadership are needed to improve, differentiate, and widen access to HEMs Effective patient education could help to reduce some of the current burden facing GPs through increasing self-management and appropriate use of healthcare services, with the introduction of WiFi into general practices as an opportunity to update health education in the waiting room and, in addition, remote consultations could be easily linked with online HEMs. As the movement towards practice federations continues, national and local producers of HEMs should target educational materials towards these groups, and federations should consider creating a role with specific training and responsibilities for patient education.

the variety, number, and topics of HEMs availablein theWRs, theaccessibility of health information lassessed against relevant guidelines), ${ }^{17,18}$ and the representativeness of the HEMs present (further information is available from the authors on request). The number of different varieties of HEMs, and the topics represented by them, were recorded. Practice characteristics and freetext comments from the researcher were also collected. The audit was conducted at a time when no participants were completing questionnaires.

\section{Study size}

The sample size calculation for this study was based on a previous study. ${ }^{16}$ Details of the sample size calculation are available from the authors on request.

\section{Statistical analysis}

Data were analysed using SPSS (version 24). Binary multiple logistic regression analysis was used to examine which predictors were independently associated with the primary outcome measures. Likert scale responses to the statements assessing the primary outcome measures were merged to form two categories: 'agreed' and 'did not agree'. Results were considered significant at the $5 \%$ level. The following variables were included in the model: age, sex, racial background, sexual orientation, smoking status, highest level of education, disability,
English as a first language, number of general practice visits in the last 6 months, waiting time before previous appointment, use of written, electronic, and face-to-face sources of health-related information, and a description of whether the patient reported reading, using electronics, or doing nothing in the WR. Descriptive statistics were used to examine the variety, number, topics, and accessibility of HEMs in the WR. Missing data were included in the descriptive analysis of questionnaire responses and were excluded listwise in the regression model. Word clouds were generated using https://www.wordclouds.com/.

\section{RESULTS}

\section{Results from the questionnaire survey}

Study setting and participants. In all, 19 (14 single-site and five multisite) of the 44 practices in Brighton and Hove agreed to participate in the study (participation rate 43.2\%). Altogether, the survey was carried out in 27 WRs of the 19 practices. The mean number of full-time equivalent leight sessions per week) general practices was 3.96 (SD \pm 2.44 ), and the mean number of registered patients per practice was 8162 (SD \pm 5412 ).

In total, 845 patients were approached, of whom 669 were eligible, and 568 agreed to take part. Of these, 556 questionnaires were completed, giving a response rate of $83.1 \%$ of those eligible. Reasons for exclusion of potential participants were: not having attended the practice in the last 6 months $(n=86)$, being unable to complete the questionnaire independently I $n=34$, of whom 27 had poor eyesight and/ or had forgotten their spectacles), being $<18$ years of age $(n=11)$, and other reasons ( $n=45)$. Reasons for declining to participate were: no reason given $(n=56)$, feeling that there was not enough time before their appointment $(n=16)$, and other reasons $(n=29)$.

The mean age of participants was 49.3 years (SD \pm 18.9 ), and $62.6 \%$ of participants were female; $90.5 \%$ of participants were white, and $87.5 \%$ had English as their first language. On average, participants spent 15.6 minutes (SD \pm 14 .1) in the WR, and the mean number of visits to the practice in the previous 6 months had been 4.6 (range 0-180) (Table 1).

Usefulness, noticeability, and attractiveness. The statement "/ normally notice posters, leaflets, and other information on display in the waiting room' was agreed with by $77.9 \%$ of participants, and $68.4 \%$ agreed with '/ find posters and/ 


\section{Table 1. Participant demographics}

\begin{tabular}{|c|c|}
\hline \multicolumn{2}{|l|}{ Age, years $(n=544)$} \\
\hline Mean (SD) & $49.27( \pm 18.87)$ \\
\hline Range & 18-92 \\
\hline \multirow[t]{2}{*}{ Unanswered } & $n=12(2.2 \%))$ \\
\hline & $N(\%)$ \\
\hline \multicolumn{2}{|l|}{$\operatorname{Sex}(n=556)^{a}$} \\
\hline Male & 196 (35.3) \\
\hline Female & $348(62.6)$ \\
\hline Unanswered & $12(2.2)$ \\
\hline \multicolumn{2}{|l|}{ Ethnicity $(n=556)$} \\
\hline White & 503 (90.5) \\
\hline Non-white & $46(8.4)$ \\
\hline Unanswered & $7(1.3)$ \\
\hline \multicolumn{2}{|l|}{ Sexual orientation $(n=556)$} \\
\hline Heterosexual & 470 (84.5) \\
\hline Non-heterosexual & $73(13.1)$ \\
\hline Unanswered & $13(2.4)$ \\
\hline \multicolumn{2}{|l|}{ Smoking status $(n=556)$} \\
\hline Ever smoked & 326 (58.8) \\
\hline Never smoked & 228 (41.2) \\
\hline Unanswered & $2(0.4)$ \\
\hline \multicolumn{2}{|c|}{ Day-to-day activities limited by a long-term health condition ( $n=556$ ) } \\
\hline Limited by disability & 209 (37.6) \\
\hline No disability & 335 (60.3) \\
\hline Unanswered & $12(2.2)$ \\
\hline \multicolumn{2}{|l|}{ Highest level of education ( $n=556$ ) } \\
\hline No qualifications & $113(20.3)$ \\
\hline Below university level education & $201(36.2)$ \\
\hline Above university level education & $231(41.5)$ \\
\hline Unanswered & $11(2.0)$ \\
\hline \multicolumn{2}{|c|}{ Sources of health information ( $n=556)$} \\
\hline Written HEMs & $166(29.9)$ \\
\hline Electronic HEMs & $422(75.9)$ \\
\hline Face-to-face information & $447(80.4)$ \\
\hline Unanswered & $6(1.1)$ \\
\hline \multicolumn{2}{|l|}{ Activity in the waiting room $(n=556)$} \\
\hline Reading & $305(54.9)$ \\
\hline Using electronic media & 313 (56.3) \\
\hline Nothing, or other & $201(36.2)$ \\
\hline Unanswered & $6(1.1)$ \\
\hline
\end{tabular}

or leaflets in the waiting room useful'. Only $47.1 \%$ of participants agreed with the statement 'The displays in the waiting room are well-designed and attractive' (Table 2).

More than half of participants in WRs with TV screens stated that they usually watched it, and only half of all WRs contained a TV screen. In the WR, more participants reported using their mobile (52\%) than any other activity, and the internet (72\%) was the second most common source of health information.

Multivariate analysis. Results from the multiple logistic regression are presented in Table 3. Participants with university-level education and above were significantly less likely to find HEMs useful lodds ratio [OR] $0.33,95 \%$ confidence interval $[\mathrm{Cl}]=0.16$ to 0.67) compared with those who were less qualified. Additionally, patients who used written HEMs were more than twice as likely to find them useful IOR 2.21, 95\% $\mathrm{Cl}=1.31$ to 3.74 ), and those who read in the WR were 1.8 times more likely to find HEMs useful (OR 1.83, 95\% Cl=1.14 to 2.94). Noticeability was negatively associated with being male (OR $0.58,95 \% \mathrm{Cl}=0.34$ to 1.00 ). 
Table 2. Patients' use and perceptions of health education materials, $\mathrm{N}=556$

\begin{tabular}{|c|c|c|c|c|c|c|}
\hline Statement & $\begin{array}{l}\text { Strongly } \\
\text { agree, } n(\%)\end{array}$ & $\begin{array}{l}\text { Agree, } \\
n(\%)\end{array}$ & $\begin{array}{l}\text { Neither agree } \\
\text { nor disagree, } n(\%)\end{array}$ & $\begin{array}{l}\text { Disagree, } \\
n(\%)\end{array}$ & $\begin{array}{c}\text { Strongly } \\
\text { disagree, } n(\%)\end{array}$ & $\begin{array}{l}\text { Did not } \\
\text { answer, } n(\%)\end{array}$ \\
\hline I often talk to my doctor about information I have found from other sources & $45(8.1)$ & $136(24.5)$ & $158(28.4)$ & $132(23.7)$ & $67(12.1)$ & 18 (3.2) \\
\hline $\begin{array}{l}\text { I normally notice posters, leaflets, and other information on display in } \\
\text { the waiting room }\end{array}$ & 105 (18.9) & $328(59.0)$ & 65 (11.7) & $30(5.4)$ & $7(1.3)$ & $21(3.8)$ \\
\hline I often read the posters and/or leaflets on display in the waiting room & $76(13.7)$ & $288(51.8)$ & $100(18.0)$ & 53 (9.5) & $13(2.3)$ & $26(4.7)$ \\
\hline $\begin{array}{l}\text { I usually understand the information in posters and/or leaflets in the } \\
\text { waiting room }\end{array}$ & 136 (24.5) & $323(58.1)$ & 64 (11.5) & $11(2.0)$ & $3(0.5)$ & $19(3.4)$ \\
\hline I find posters and/or leaflets in the waiting room useful & 102 (18.3) & $280(50.4)$ & $139(25.0)$ & 18 (3.2) & $5(0.9)$ & $12(2.2)$ \\
\hline $\begin{array}{l}\text { I often watch the TV screen and/or listen to audio resources in the } \\
\text { waiting room }\end{array}$ & 33 (5.9) & $107(19.2)$ & 53 (9.5) & $49(8.8)$ & $14(2.5)$ & $300(54.0)^{\mathrm{a}}$ \\
\hline The displays in the waiting room are well-designed and attractive & $50(9.0)$ & $212(38.1)$ & $204(36.7)$ & $56(10.1)$ & $4(0.7)$ & $30(5.4)$ \\
\hline I can identify with the health education materials on display & $57(10.3)$ & $247(44.4)$ & $195(35.1)$ & $31(5.6)$ & 3 (0.5) & $23(4.1)$ \\
\hline $\begin{array}{l}\text { Health education materials in the waiting room are valuable for } \\
\text { improving my overall health and wellbeing }\end{array}$ & $65(11.7)$ & $236(42.4)$ & $190(34.2)$ & $43(7.7)$ & $4(0.7)$ & 18 (3.2) \\
\hline
\end{tabular}

This response number includes participants from WRs without a screen. No practices provided audio resources (not including background music or commercial radio stations).

Patients who read in the waiting room were more likely to notice HEMs IOR 3.29, $95 \%$ $\mathrm{Cl}=1.80$ to 6.00$)$. Participants with a longer waiting time (OR $0.98,95 \% \mathrm{Cl}=0.97$ to 1.00 ),

\section{Table 3. Logistic regression on perceptions of health education materials with patient-related variables ${ }^{\mathrm{a}}$}

\begin{tabular}{|c|c|c|c|}
\hline Independent variable & $P$-value & OR & $95 \% \mathrm{Cl}$ \\
\hline \multicolumn{4}{|l|}{ Usefulness } \\
\hline \multicolumn{4}{|c|}{ I find posters and/or leaflets in the waiting room useful } \\
\hline Written HEMs & $0.003^{b}$ & 2.214 & 1.311 to 3.739 \\
\hline Reading in the WR & 0.012 & 1.834 & 1.144 to 2.940 \\
\hline \multicolumn{4}{|l|}{ Education } \\
\hline No qualifications & 0.006 & & \\
\hline Below university level & 0.069 & 0.524 & 0.261 to 1.051 \\
\hline University level and above & 0.002 & 0.331 & 0.164 to 0.669 \\
\hline \multicolumn{4}{|l|}{ Noticeability } \\
\hline \multicolumn{4}{|c|}{ I normally notice posters, leaflets, and other information on display in the waiting room } \\
\hline Sex (male) & 0.048 & 0.581 & 0.340 to 0.995 \\
\hline Reading in the WR & 0.000 & 3.290 & 1.804 to 6.000 \\
\hline \multicolumn{4}{|l|}{ Attractiveness } \\
\hline \multicolumn{4}{|c|}{ The displays in the waiting room are well-designed and attractive } \\
\hline Waiting time & 0.043 & 0.984 & 0.970 to 1.000 \\
\hline \multicolumn{4}{|l|}{ Education } \\
\hline No qualifications & 0.048 & & \\
\hline Below university level & 0.128 & 0.625 & 0.342 to 1.144 \\
\hline University level and above & 0.015 & 0.470 & 0.256 to 0.864 \\
\hline
\end{tabular}

a Logistic regression including the following variables: age, sex (male/female), racial background (white/non-white), sexual orientation (heterosexual/non-heterosexual), smoking status (ever smoked/never smoked), education (university level and above/below university level/no qualifications), disability (limited/not limited), English as first language (yes/no), general practice visits in last 6 months, waiting time, written HEMs (yes/no), electronic HEMs (yes/no), face-to-face health information (yes/no), reading in the waiting room (yes/no), using electronics in the waiting room (yes/no), nothing/other in the waiting room (yes/no). ${ }^{b}$ Results in bold indicate statistical significance $(P<0.05)$. HEM = health education material. $O R=$ odds ratio. $W R=$ waiting room. and those with university-level education and above (OR $0.47,95 \% \mathrm{Cl}=0.26$ to 0.86 ) were significantly less likely to find HEMs attractive.

\section{Results from the audit}

Number and topics of health education materials. On average, there were 72 posters covering 23 topics; and 53 leaflets covering 24 topics. The most commonly available topics of HEMs were relating to service provision, patient involvement, cancer and screening, mental health, and safeguarding and abuse. Figures 1-3 present word clouds displaying the frequency of topics found in posters, leaflets, or on television screens.

The mean review frequency for displays in the WR was 7.8 weeks (SD \pm 8.3 weeks), although this was stated by the practice staff rather than observed by the researcher, and three practices stated that the WR was never reviewed. The person most commonly responsible for reviewing and updating HEMs was the practice manager (57.9\%). Others responsible included administrative staff, patient participation groups, healthcare assistants, commercial leaflet companies, GPs, nurses, and 'nobody'. In nine practices, more than one person was responsible. The researcher's written observations noted a large amount of outof-date information ( $n=25$ comments), blank displays, duplicated posters, closed leaflets pinned to noticeboards, out-ofuse television screens $(n=5)$, posters targeted at staff, and other poor utilisation 


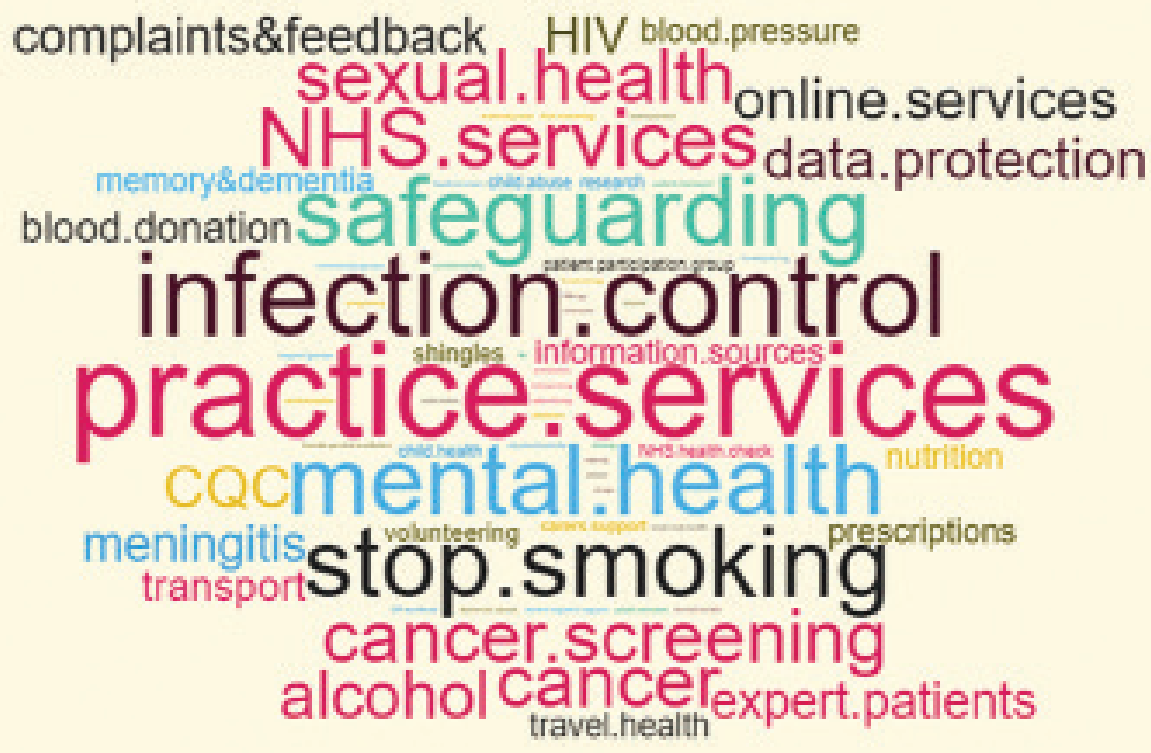

Figure 1. Word cloud displaying topics of health education materials on posters.

Figure 2. Word cloud displaying topics of health education materials on leaflets. of resources, such as displaying matching posters and leaflets separately, and using glossy laminate that reflects light, rendering posters difficult to read ( $n=12$ comments).

Accessibility and design of health education materials. The provision of HEMs in accessible formats was generally poor with a mean score of $8.74 / 35$ for posters, and $13.21 / 35$ for leaflets. No posters were provided in braille, audio, or video formats in any WR lall had a mean score of 1 on the audit tool), and very few leaflets were available in video format (mean score 1.13). In many cases, braille, audio, or foreignlanguage formats of leaflets were available to order from the producer but were not physically present in the WR. The mean design score was 35.90/45 for posters, and $34.08 / 45$ for leaflets. The highest scoring criterion for both posters and leaflets was Bold type or colours used for headings or to accentuate meaning' (means 4.85 and 4.96, respectively). The lowest scoring criteria were Materials represent patient groups of varying age, sex, ethnicity, sexuality, and disability for posters' (mean 2.85), and 'Font size 14 or more' for leaflets (mean 2.00).

\section{DISCUSSION}

\section{Summary}

To the authors' knowledge, this is the first study to combine patient opinion with assessment of the availability and quantity of HEMs in general practice WRs. They appear to be a forgotten and underresourced corner of health promotion, with little national or local oversight, and no mention of HEMs in the Quality and Outcomes Framework (QOF), Care Quality Commission (CQC) inspections, or general practice contracts. There is substantial variation in the amount, topicality, and quality of material available in WRs, with a variety of people, or even nobody, responsible for the provision or updating of WR information in some practices.

There also appears to have been little effort to systematically utilise available technology to widen access to information by linking into existing databases of validated information, differentiating information according to health literacy levels and/or the interests of the patient, and providing translated materials. Despite this, most patients reported that they notice HEMS and find them useful, although it appeared that fewer patients find them to be welldesigned and attractive.

The authors found a wide variety of HEMs available in the WR. Usefulness was associated with reading in the WR, using written HEMs as a source of health information, and not having a university degree. Noticeability was associated with reading in the WR, and being female. Attractiveness was associated with not having a university degree and shorter waiting time. The quality of HEMs available was highly variable. WRs scored highly on the design components of the audit tool. However, there was poor provision of information in accessible and foreignlanguage formats.

With the recent decision to provide free wireless free internet (Wi-Fi) in general practices in England, it may be time to review the materials on offer in general practice waiting rooms. 


\section{blood.tests contact.information \\ information. sources ${ }^{\text {opening.hours }}$ organ.donation SeXUal.health contraception long-term conditions diabetes expert.patients bowel.cancer sun.exposure NHS.Services carers.support breast.cancer child.health Practice.SerVICeS weight.management patient. participation.group stop.smokingalCOhO| chaperones cancer prescriptions youth.services breast.awareness cancer.screening research lung.cancer carers.supportphysical.activity confidentiality volunteering Online.SerVices ${ }_{\text {mental.health }}^{\text {NHS. check }}$ memory\&dementia concerning.symptoms special.educational.needs complaints\&feedback}

Figure 3. Word cloud displaying topics of health education materials on television screens.

\section{Strengths and limitations}

This study involved nearly half of the general practices in Brighton and Hove (43\%), and was successful in recruiting 556 patients from these practices, achieving a high response rate. The questionnaire was piloted, and included patients visiting various professionals, therefore collecting a range of viewpoints. Additionally, rather than focusing on a single form of information, this study included all HEMs in the WR and, to the authors' knowledge, no other study has assessed the accessibility of HEMs in this way.

The sample size calculation for this study accounted for intra-cluster correlation, and the authors used linear mixed modelanalysis to examine clustering of questionnaire responses by practice location (further information available from the authors on request). The analysis suggested that there was minimal clustering of participant responses by practice.

Though the overall sample size was achieved, the authors failed to recruit the desired number of practices, which may have affected the power of the study. Roughly the same number of participants were recruited from each practice, irrespective of the size of the practice, which overrepresents smaller practices. Also, all practices involved were from Brighton and Hove, suggesting the findings might have some limitations regarding generalisability to other settings. However, because the sample size was large, a range of practices was included, and the participant characteristics were similar to those of the local population, the findings of this study are likely to be generalisable to WRs in other locations.

The questionnaire was piloted, but it was not validated. Furthermore, the eligibility criteria excluded first-time or infrequent attenders as they would not have experience to base their responses on. However, these groups are also targets for health education.

Finally, this study does not explore the effectiveness of HEMs at increasing knowledge and changing behaviours, though this has been evaluated elsewhere.

\section{Comparison with existing literature}

More than two-thirds of participants in this study agreed that they found posters and/ or leaflets in the WR useful, which is double the proportion found by Moerenhout et al in 2013. ${ }^{16}$ This study also agreed that reading in the WR or using written HEMs were positively associated with usefulness. ${ }^{16}$ In contrast, however, the authors of the current study found that having a university degree was negatively associated with usefulness, ${ }^{16}$ in spite of previous findings that only $24.3 \%$ of leaflets in the UK meet recommended reading level criteria. ${ }^{19}$ More than three-quarters of patients noticed HEMs in the WR, a finding that is similar to other studies from the UK. 9.10 Men were less likely than women to notice HEMs, which could be related to lower health literacy in men. ${ }^{20}$ The number of posters and leaflets present was higher than that reported in previous studies, although these studies took place outside of the UK. ${ }^{16,21,22}$

\section{Implications for research and practice}

More than two-fifths of participants in WRs with TV screens stated that they usually watched it. Despite substantial evidence that educational videos in the WR lead to positive outcomes, ${ }^{13,23-27}$ only half of all WRs contained a TV screen.

Furthermore, in several WRs the screen was turned off, or playing commercial television or advertisements, and none played sound. TV screens are a potentially effective educational resource that currently seem underutilised.

In the WR, more participants reported using their mobile (52\%) than any other activity, and the internet (72\%) was the second most common source of health information. As $81 \%$ of adults in the UK now own a smartphone, and $54 \%$ have access to $4 G_{1}^{28}$ this represents a future target for WR educational interventions. Some HEMs contained a Quick Response (QR) code linking to a website with more information. In the future, this could be used to link to reliable online sources of 


\section{Funding}

This study received no external funding. Katherine Maskell was awarded a Wolfson Foundation Intercalated Degree Research Fellowship of $€ 5000$ from the Royal College of Physicians to undertake this research.

\section{Ethical approval}

A favourable ethical opinion and Health Research Authority (HRA) approval were obtained via the Integrated Research Approval System (IRAS) (project ID: 217441). Institutional sponsorship was obtained from the University of Sussex, and Brighton and Hove Clinical Commissioning Group (CCG) gave their support for the study.

\section{Provenance}

Freely submitted; externally peer reviewed.

\section{Competing interests}

The authors have declared no competing interests.

\section{Acknowledgements}

This study was conducted as Katherine Maskell's dissertation for the University of Brighton MSc in Public Health in the Department of Medical Education at the Brighton and Sussex Medical School. The authors thank the patients who took part in this study, and the general practices granting access to their waiting rooms.

\section{Discuss this article}

Contribute and read comments about this article: bjgp.org/letters

health information. The provision of HEMs in accessible formats and foreign languages was extremely limited, despite patients desire for this. ${ }^{13,21}$ Also, almost no HEMs in alternative formats were physically present in the WR, although many were available on request from the producer of the HEM. A database in the WR could provide translated materials and be linked to a print- or emailon-demand system. These technologies could be used to provide more effective, personalised, targeted health information. ${ }^{2}$ As groups of practices work together to care for larger populations of patients, and remote access to health care becomes more common, traditional health promotion strategies based around the face-to-face consultation may need to change. Online resources are easy to signpost patients to, and many practices already have websites that could be used for this purpose. Electronic health education may allow a broad population of patients to access accurate, high-quality, and potentially personalised health information at a time and place of their choosing, although this may not be suitable or preferable for all patients. For example, in 2017, the Office for National Statistics found that only $41 \%$ of adults aged $>75$ years had used the internet in the previous 3 months. ${ }^{29}$

Despite practices reporting that the contents of WRs were reviewed regularly, there were many examples of out-of-date information. In one practice, it was nobody's responsibility to maintain and update the WR, and in many practices a variety of staff members were tasked with this, which may reflect a lack of importance attached to health education in the WR. This could be addressed by creating a role within the practice with responsibility for managing patient education and associated training for this. Most practices produced very few, if any, of their own HEMs, and many were provided by national or local charities and organisations. This suggests that the variable quality of the HEMs may not be due to the practices, but the producers and distributors of the information. One could argue that those responsible for displaying HEMs in their WR ought to assess their accuracy and quality before distributing them to patients. However, given the current pressures on general practice, it is unlikely that this is seen as a priority. Interventions to improve the quality of HEMs would be best targeted at these bodies producing the majority of HEMs, rather than the practices that distribute them.

There is also a need for more outcomebased research on the effectiveness of health information materials in this setting. 


\section{REFERENCES}

1. Oermann $\mathrm{MH}$. Effects of educational intervention in waiting room on patient satisfaction. J Ambul Care Manage 2003; 26(2): 150-158.

2. Friedman AJ, Cosby R, Boyko S, et al. Effective teaching strategies and methods of delivery for patient education: a systematic review and practice guideline recommendations. J Cancer Educ 2011; 26(1): 12-21.

3. Wegwarth O, Kurzenhauser-Carstens S, Gigerenzer G. Overcoming the knowledge-behavior gap: the effect of evidence-based HPV vaccination leaflets on understanding, intention, and actual vaccination decision. Vaccine 2014; 32(12): 1388-1393.

4. de Haan MC, de Wijkerslooth TR, Stoop E, et al. Informed decision-making in colorectal cancer screening using colonoscopy or CT-colonography. Patient Educ Couns 2013; 91(3): 318-325.

5. van Agt HM, Korfage IJ, Essink-Bot ML. Interventions to enhance informed choices among invitees of screening programmes - a systematic review. Eur $J$ Public Health 2014; 24(5): 789-801.

6. Coulter $A$. Evidence-based patient information is important, so there needs to be a national strategy to ensure it. BMJ 1998; 317(7153): 225-226.

7. Shank JC, Murphy M, Schulte-Mowry L. Patient preferences regarding educational pamphlets in the family practice center. Fam Med 1991; 23(6): 429-432.

8. Elliott BJ, Polkinhorn JS. Provision of consumer health information in general practice. BMJ 1994; 308(6927): 509-510.

9. Ward K, Hawthorne K. Do patients read health promotion posters in the waiting room? A study in one general practice. Br J Gen Pract 1994; 44(389): 583-585.

10. Wicke DM, Lorge RE, Coppin RJ, Jones KP. The effectiveness of waiting room noticeboards as a vehicle for health education. Fam Pract 1994; 11(3): 292-295.

11. Natt N, Klar E, Cheung I, et al. Increasing organ donor registration in a primary care clinic. BMJ Qual Improv Rep 2017; 6(1): u222401.w8341.

12. Shah A, Scogin F, Pierpaoli CM. Older adults' attitudes toward depression screening in primary care settings and exploring a brief educational pamphlet. Int J Geriatr Psychiatry 2018; 33(1): e40-e48.

13. Jawad M, Ingram S, Choudhury I, et al. Television-based health promotion in general practice waiting rooms in London: a cross-sectional study evaluating patients' knowledge and intentions to access dental services. BMC Oral Health 2016; 17(1): 24

14. Eubelen $C$, Brendel F, Belche JL, et al. Effect of an audiovisual message for tetanus booster vaccination broadcast in the waiting room. BMC Fam Pract 2011; 12: 104.

15. Makoul G, Cameron KA, Baker DW, et al. A multimedia patient education program on colorectal cancer screening increases knowledge and willingness to consider screening among Hispanic/Latino patients. Patient Educ Couns 2009; 76(2): 220-226.

16. Moerenhout T, Borgermans L, Schol S, et al. Patient health information materials in waiting rooms of family physicians: Do patients care? Patient Prefer Adherence 2013; 7: 489-497.

17. Office for Disability Issues, Department for Work and Pensions. Accessible communication formats. 2014. https://www.gov.uk/government/publications/ inclusive-communication/accessible-communication-formats laccessed 10 Oct 2018).

18. European Commission. Enterprise and Industry Directorate-General. Guideline on the readability of the labelling and package leaflet of medicinal products for human use. 2009. http://ec.europa.eu/health/files/eudralex/vol-2/c/2009 0112 readability_guideline_final_en.pdf laccessed 10 Oct 2018).

19. Protheroe J, Estacio EV, Saidy-Khan S. Patient information materials in general practices and promotion of health literacy: an observational study of their effectiveness. Br J Gen Pract 2015; DOI: https://doi.org/10.3399/bjgp15X684013.

20. von Wagner C, Knight K, Steptoe A, Wardle J. Functional health literacy and health-promoting behaviour in a national sample of British adults. J Epidemiol Community Health 2007; 61(12): 1086-1090.

21. Beckwith $N$, Jean-Baptiste ML, Katz A. Waiting room education in a community health system: provider perceptions and suggestions. J Community Health 2016; 41(6): 1196-1203.

22. Gignon $\mathrm{M}$, Idris $\mathrm{H}$, Manaouil $\mathrm{C}$, Ganry $\mathrm{O}$. The waiting room: vector for health education? The general practitioner's point of view. BMC Res Notes 2012; 5: 511

23. Koperski M. Health education using video recordings in a general practice waiting area: an evaluation. J R Coll Gen Pract 1989; 39(325): 328-330.

24. Oermann MH, Webb SA, Ashare JA. Outcomes of videotape instruction in clinic waiting area. Orthop Nurs 2003; 22(2): 102-105

25. Krouse HJ. Video modelling to educate patients. J Adv Nurs 2001; 33(6): 748-757.

26. Comite F, Gallagher TC, Villagra V, Koop CE. Patient education as medical intervention: a pilot study. HMO Pract 1998; 12(1): 17-23.

27. Tingey $P$, Khanafer $M$, Singh $K$, et al. Social persuasion in rheumatology: a randomized trial of testimonials on television in the rheumatology clinic waiting room to increase attendance for multidisciplinary education. Rheumatol Int 2014; 34(7): 903-907.

28. Deloitte. Global mobile consumer survey 2016: UK cut. 2016. http://wnw. deloitte. co.uk/mobileuk2016/ laccessed 10 Oct 2018).

29. Office for National Statistics. Statistical bulletin: internet users in the UK: 2017 2017. https://www.ons.gov.uk/businessindustryandtrade/itandinternetindustry/ bulletins/internetusers/2017 (accessed 10 Oct 2018). 